\title{
HYBRID LASER-GMA GIRTH WELDING TECHNOLOGIES FOR TRANSMISSION PIPELINES
}

\author{
S. KEITEL and J. NEUBERT \\ Schweißtechnische Lehr- und Versuchsanstalt Halle GmbH \\ 33a Koethener Str., 06118, Halle (S.), Germany. E-mail: keitel@slv-halle.de
}

\begin{abstract}
The aim of investigation of hybrid laser-arc welding lies in accumulation of knowledges about this process applicable to producing of pipe joints. Number of aspects are considered, such as tolerances, effect of environment, mobility of equipment and procedure in irregularities of position. The main attention is paid to investigation of effect of laser welding with large penetration depth in making of high-quality joint in root face of 6-10 mm. Performed is a comparison of different positions of laser beam and arc, which can be used in hybrid welding with different types of preparation for welding. Procedure of production of pipe joints lies in downhill welding of two vertical welds, that is standard practice for pipeline construction and significantly reduces degree of freedom in positioning of laser beam and arc, necessary for obtaining technological optimum parameters during joint formation. Weld bead is elongated by means of continuous movement of torch, that allows made the first pass using hybrid welding and cover pass by arc for one welding cycle in order to obtain closed seam profile in joints of up to $12 \mathrm{~mm}$ thickness. Besides, the latter process provides positive effect on mechanical properties of the weld metal. 3 Ref., 4 Tables, 8 Figures.
\end{abstract}

Keywords: hybrid laser-arc welding, pipe joint, girth welds, equipment, welding mode parameters, experiment setup

For many years well tested and proven arc processes have been applied for welding of large diameter pipes of oil-and-gas pipelines. Depending on the length of pipeline to be produced, wall thickness and materials of individual pipes, versatile variations of these processes are used with a scope extending from manual stick electrode arc welding up to orbital MAG process. In this case, movement is not performed manually by the welder but is fully mechanized using motordriven systems and clamping rings across the entire circumference of the pipe. If permitted by length of the pipeline and profile of the ground,

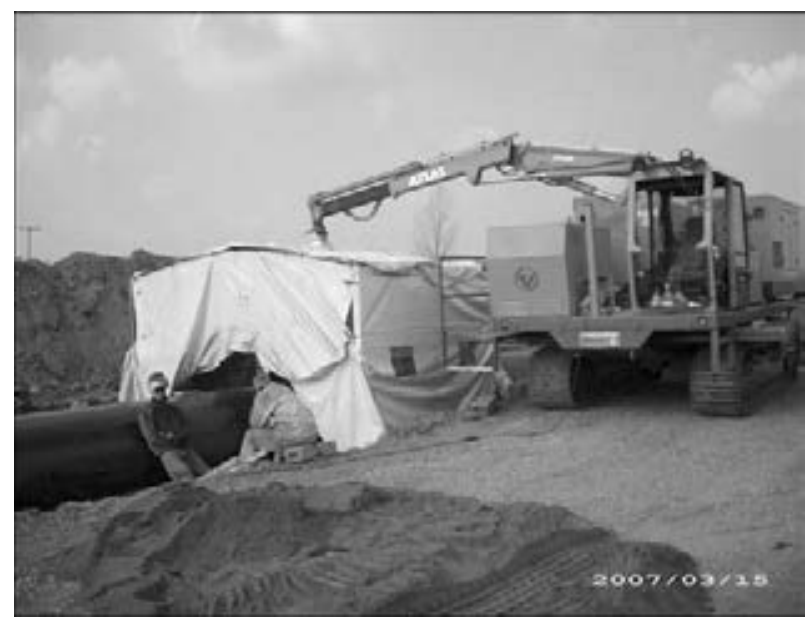

Figure 1. Building site in pipeline construction (C) S. KEITEL and J. NEUBERT, 2014 a number of these orbital units are used at the same time with every single station having been designed for one- or two-pass welding and then being displaced to the next pipe joint to produce the same weld there. Such production aggregates often rely on several welding heads per unit thus representing a high state-of-the art [1], both in relation to equipment and welding. This, however, is connected with a high expenditure on personnel and plant engineering (Figure 1).

A further increase of the performance in this area bears some problems since the arc processes applied have obtained their physical limits concerning deposition efficiency and welding speed. Here, no essential increases can be achieved by optimizing the arc welding technology.

The development of welding processes of increased performance must be carried out under the following aspects:

- reduction of the number of passes at constant and improved weld quality;

- reduction of the number of welding stations and, thus, the expenditure on equipment and personnel.

Welding processes based on laser beam, on the one hand, offer the technology and, on the other hand, the equipment needed to fulfil this demand.

Hybrid laser-GMA girth welding under conditions similar to those at construction sites. Objectives and technological approach. The objective of examinations technology and equipment described was the transfer of state of knowledge of hybrid laser-GMA welding for the pro- 
duction of pipe joints incorporating all necessary aspects such as tolerances, environmental influences, mobility of the entire equipment and welding out-of-position.

The focus of examinations was laid on the use of the laser typical deep welding effect for the production of a high quality free root pass at root faces of $6-10 \mathrm{~mm}$. To this end, the different arrangements of laser beam and arc possible for hybrid welding of butt joints were compared to the different types of joint preparation. The approach for the production of pipe joints was welding of two vertical-down seams being common practice in pipeline construction and considerably reducing the types of freedom in the arrangement of laser beam and arc required for the technological optima of the weld formation.

For the generation of a closed seam profile the welding head was extended by a further arc torch, thus enabling to weld the first pass using hybrid welding and the cover pass using GMA welding during one welding run. The objective was to produce a closed seam profile on a plate $12 \mathrm{~mm}$ thick in one rotation. Further, this trailing process is a good opportunity to have a positive influence on the mechanical-technological properties of the weld metal.

Equipment. In order to verify the principal feasibility of the laser-GMA process during girth welding the proven techniques were used. The equipment for examinations was the Gullco commercially available system for pipe welding.

This system was equipped with a tractor on a ring guide for girth welding, as well as with a contact seam tracking and scanning system based on two control axes for the transverse and height positioning of the components to the groove. The arrangement of the contact sensor forwarding the welding process was executed in direction of movement. Equipped with various stiffening elements the adaptation of the welding head to the control axles for height control was executed. For transferring the possible serial types of arrangement of laser beam and welding arc are shown in Table 1, the head for hybrid welding was equipped with additional degrees of freedom.

As shown in this Table, either the laser or the arc was considered at neutral position each, for reasons of simplification. No intermediate levels were used.

Two different fiber lasers were used as laser beam sources. In the first phase with the focus of investigation on root faces up to $6 \mathrm{~mm}, 4.5 \mathrm{~kW}$ output system was used, and for second phase at root face of $8 \mathrm{~mm}$, the SLV Mecklenburg-Vorpommern mobile $10 \mathrm{~kW}$ laser was integrated to
Table 1. Serial arrangements of laser beam and arc

\begin{tabular}{||c|c|c|c|}
\hline \multirow{3}{*}{ Variation } & $\begin{array}{c}\text { Neutral } \\
\text { process }\end{array}$ & Second process & $\begin{array}{c}\text { Schematic } \\
\text { beam } \\
\text { representation }\end{array}$ \\
\hline 2 & & $\begin{array}{c}\text { Arc forward } \\
\text { travelling }\end{array}$ & Arc trailing \\
\hline \multirow{2}{*}{3} & Arc & $\begin{array}{c}\text { Laser beam } \\
\text { forward travelling }\end{array}$ \\
\hline \multirow{2}{*}{4} & Laser beam trailing
\end{tabular}

the test built-up. The $4.5 \mathrm{~kW}$ fiber laser from the year 2003 was one of the first sources for welding within this performance class having proven its long standing stability in many applications.

Figure 2 shows the completed welding head with equipment for hybrid welding and integrated second arc torch for welding the cover pass during one vertical-down movement.

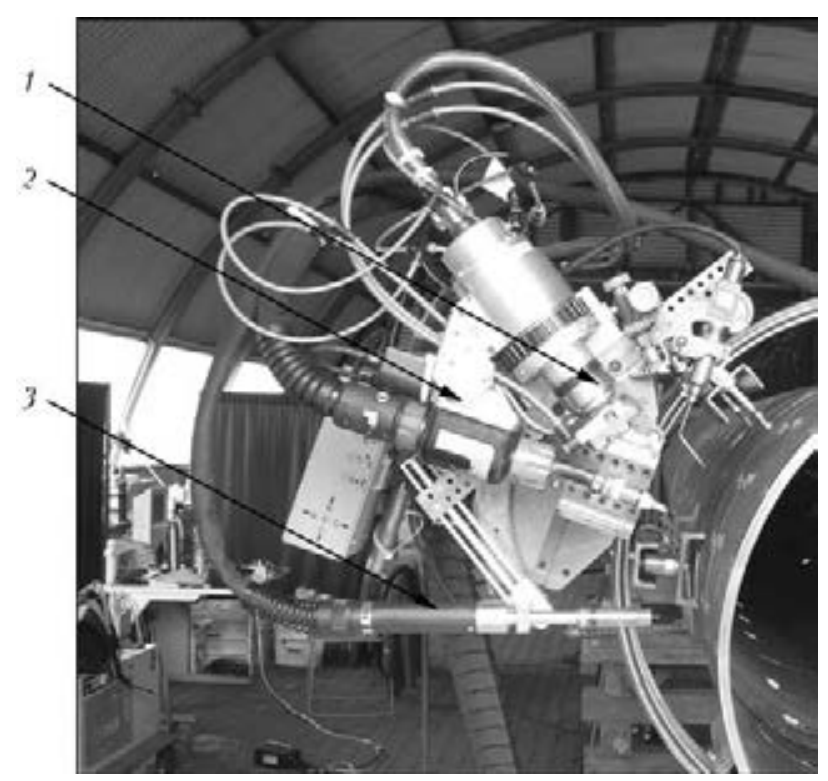

Figure 2. Welding head with hybrid equipment for root pass and arc torch for filling the groove: 1 - laser optics; 2 - hybrid arc; 3 - torch for filler pass welding 


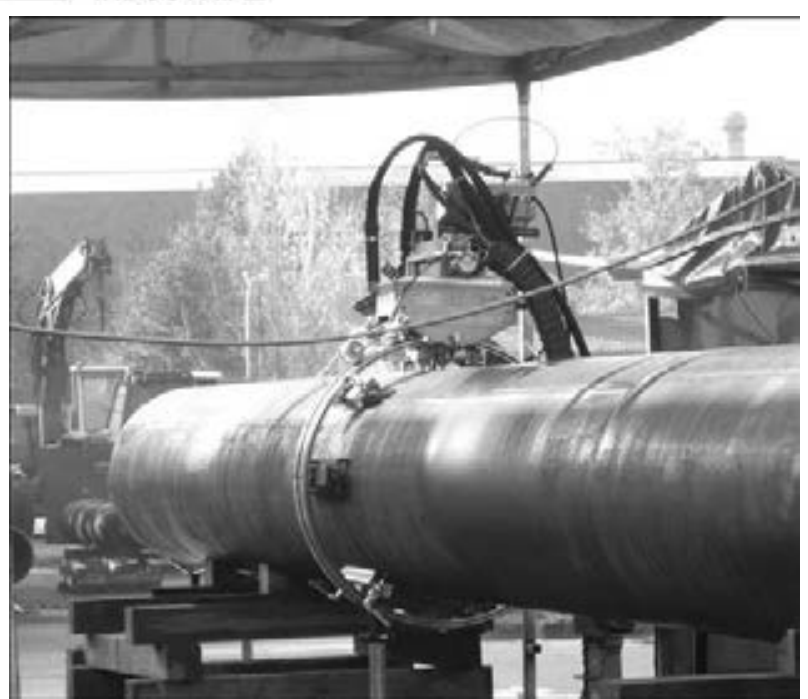

Table 2. Edge preparation and hybrid-welded joints macrosections

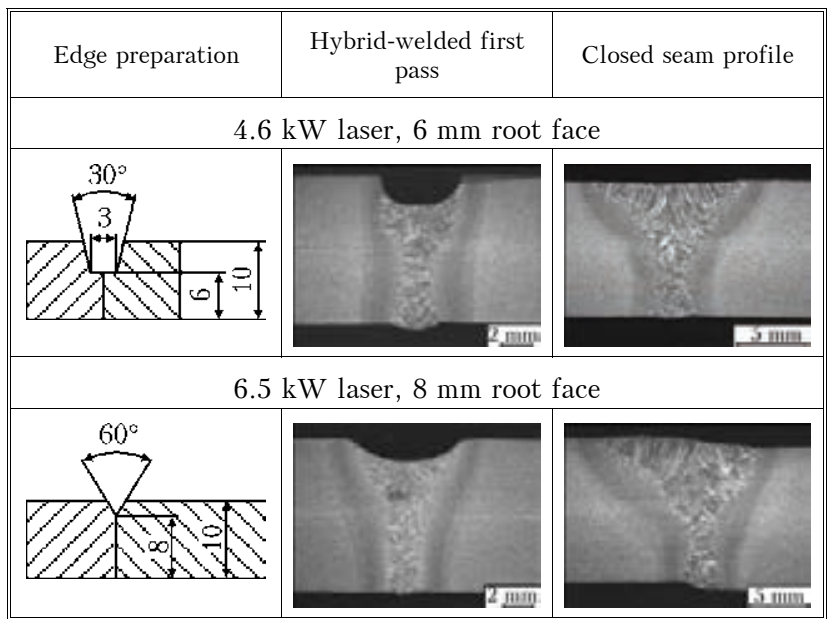

Figure 3. Entire test built-up on the pipe

Welding was performed on pipe pieces at lengths of up to $6 \mathrm{~m}$. In this case larger tolerance results compared to pipe with calibrated ends, in particular, with regard to quality and misalignment of edges.

Through the integration of the components described the entire test set-up, shown in $\mathrm{Fi}_{-}$ gure 3, was realized.

Execution and results of the technological examinations. The test was performed using two laser beam sources of different output. In doing so, first the principal test series for determining the basic parameters for hybrid arc and for determining the tolerance susceptibility of hybrid process at continuously changing welding positions across the pipe circumference was performed in first phase using the $4.5 \mathrm{~kW}$ fiber laser. Second test phase served to estimate the potential of hy-

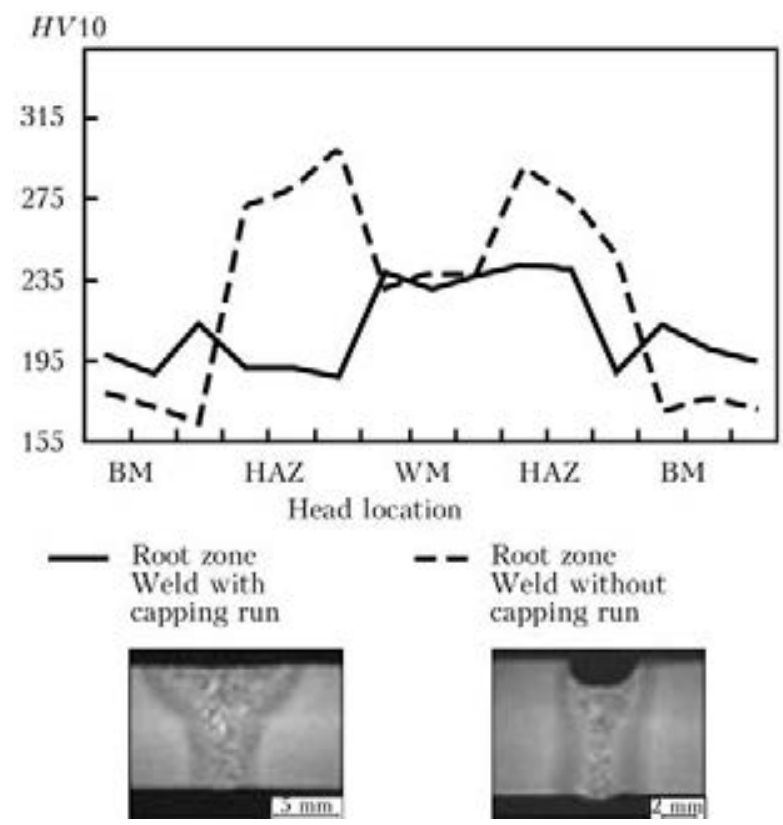

Figure 4. Influence of hardness distribution in the root zone on welding head location [2]

brid process at higher laser performance at simultaneous increase of root faces for the root pass of 6-8 $\mathrm{mm}$. To his end, the $10 \mathrm{~kW}$ fiber laser system was used.

In the following the results are shown in the form of macrosections both for the first hybrid pass and the closed seam profile, performed by trailing arc at different variation of edge preparation at laser output of 4.6 and $6.5 \mathrm{~kW}(\mathrm{Ta}-$ ble 2). Through the tolerances, measured at pipe joints and welding parameters assigned today, there are considerable results on the different tolerances of the process.

The examinations were concluded by the determination of hardness distribution, in particular in the root area of welds, since this obviously laser beam dominated area in HAZ could be susceptible to increased hardening. During these examinations, pure root welding without cover pass was compared to welding with closed seam profile through the trailing arc. Obtained results are shown in Figure 4.

A decisive object of investigation was the determination of typical tolerances in pipeline construction and the examination of influence of these tolerances on the hybrid welding process. During the trials the pipe joints were positioned and fixed using typical tools, and methods resulting in tolerances typical of pipeline construction. In order to draw conclusions from these tolerances during the future evaluations, the joining edges and welded joints were measured.

Further development of equipment and technology. The major objective of the investigations shown was to prove the principal suitability of hybrid welding for pipeline construction with regard to the more rough climatic conditions in this field of application. Here, important information 
with a great influence on the structural design of equipment was obtained. The specialized prototype developed on the basis of this for realization of girth movement in hybrid laser-GMA welding (Figure 5) has the following technical data: up to $6 \mathrm{~m} / \mathrm{min}$ travelling speed at positioning and up to $3 \mathrm{~m} / \mathrm{min}$ in welding; processed pipe diameters of $500-700 \mathrm{~mm}$; change of parameters depending on position; seam tracking and guidance system.

The integrated laser working head allows coupling with all fiber-guided solid-state lasers of up to $20 \mathrm{~kW}$ outputs.

The focus of the examinations, on the one hand, was directed to investigate the possibilities of formation of the weld and root with the laser output available and, on the other hand, on the overlapped areas at the weld start obligatory when welding two vertical-down seams at the circumference of pipe.

This phase of examinations was concluded by the performance on material tests for determining the mechanical-technological characteristic values for the L360NB test steel. The results of tensile test and $\mathrm{V}$-notched bar impact test at temperature of $0{ }^{\circ} \mathrm{C}$ is shown in Table 3 .

Laser girth welding and in-process testing of small diameter pipe joints with wall thickness of $3-\mathbf{5} \mathbf{~ m m}$. The objective of the second research project was a prototype for laser welding that should be developed and will allow a combined solution for the welding and testing of small diameter steel pipes with the aid of orbital process. The development effort in this situation consists of the combining different test techniques, in order finally to achieve a degree of reliability of results appropriate to the area of application.

Right from the start, the prototype was to be based on a design, which was as easy to handle as possible, and as space-saving as could be achieved. With an eye to the areas of application, which have already been described, as a first step a rated wall thickness range of the steel pipes from 3 to $5 \mathrm{~mm}$ was covered, this finally corresponds to the application range of pipe external diameters from 100 to about $400 \mathrm{~mm}$. The per-

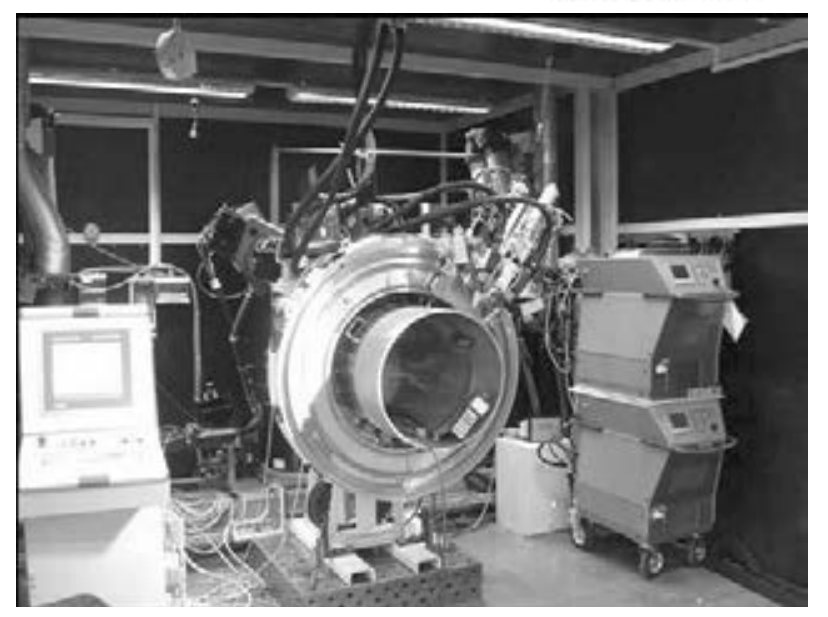

Figure 5. Specialized prototype equipment for pipeline welding

missible tolerances for welding gap and detectable sizes of irregularities, acquired by the test technology, are to be determined.

The construction equipped with testing and welding technology for the pipe joining is to be kept distinct from the equipment required for generation of the welding energy and for processing the measurement signals. The connection is to be produced by an appropriately arranged service line. In this way, even considerable distances can be covered between the equipment technology and actual workplace. This means that, depending on the area of application, the equipment can be installed on a site vehicle.

Experimental setup and procedure. To resolve the basic task successfully, it was, first of all, necessary to design the device for carrying out the circumferential movement of laser optics, as well as the device had to provide sufficient space for the sensor system for process monitoring and non-destructive testing. In this context, the focus of the investigations was set on creation of unitary monitoring and testing strategy, which would provide an analysis of weld quality, achieved directly after the welding completion. The information required for this can be acquired before, during and after the welding process in the form of different signals. The analysis of irregularities in laser-welded joints shows that the majority of these are attributable to interference in the process sequence. The cause of these, in turn, is the

Table 3. Mechanical properties of the L360NB steel welded joints

\begin{tabular}{|c|c|c|c|c|c|c|c|c|c|c|}
\hline \multicolumn{5}{|c|}{ Tensile test } & \multicolumn{6}{|c|}{$\mathrm{V}$-notched bar impact test at $T=0{ }^{\circ} \mathrm{C}$} \\
\hline \multirow{2}{*}{$\sigma_{0.2}, \mathrm{MPa}$} & \multirow{2}{*}{$\sigma_{t}, \mathrm{MPa}$} & \multirow{2}{*}{$\delta, \%$} & \multirow{2}{*}{$\psi, \%$} & \multirow{2}{*}{ Fracture site } & \multicolumn{2}{|c|}{ Dimensions, mm } & \multicolumn{4}{|c|}{$K C V, \mathrm{~J}$} \\
\hline & & & & & Width & Height & 1 & 2 & 3 & Mean \\
\hline 345 & 532 & 42 & 71 & BM & 7.5 & 8.0 & 201 & 128 & 77 & 136 \\
\hline 368 & 539 & 39 & 69 & BM & 7.5 & 8.0 & 180 & 181 & 169 & 177 \\
\hline
\end{tabular}




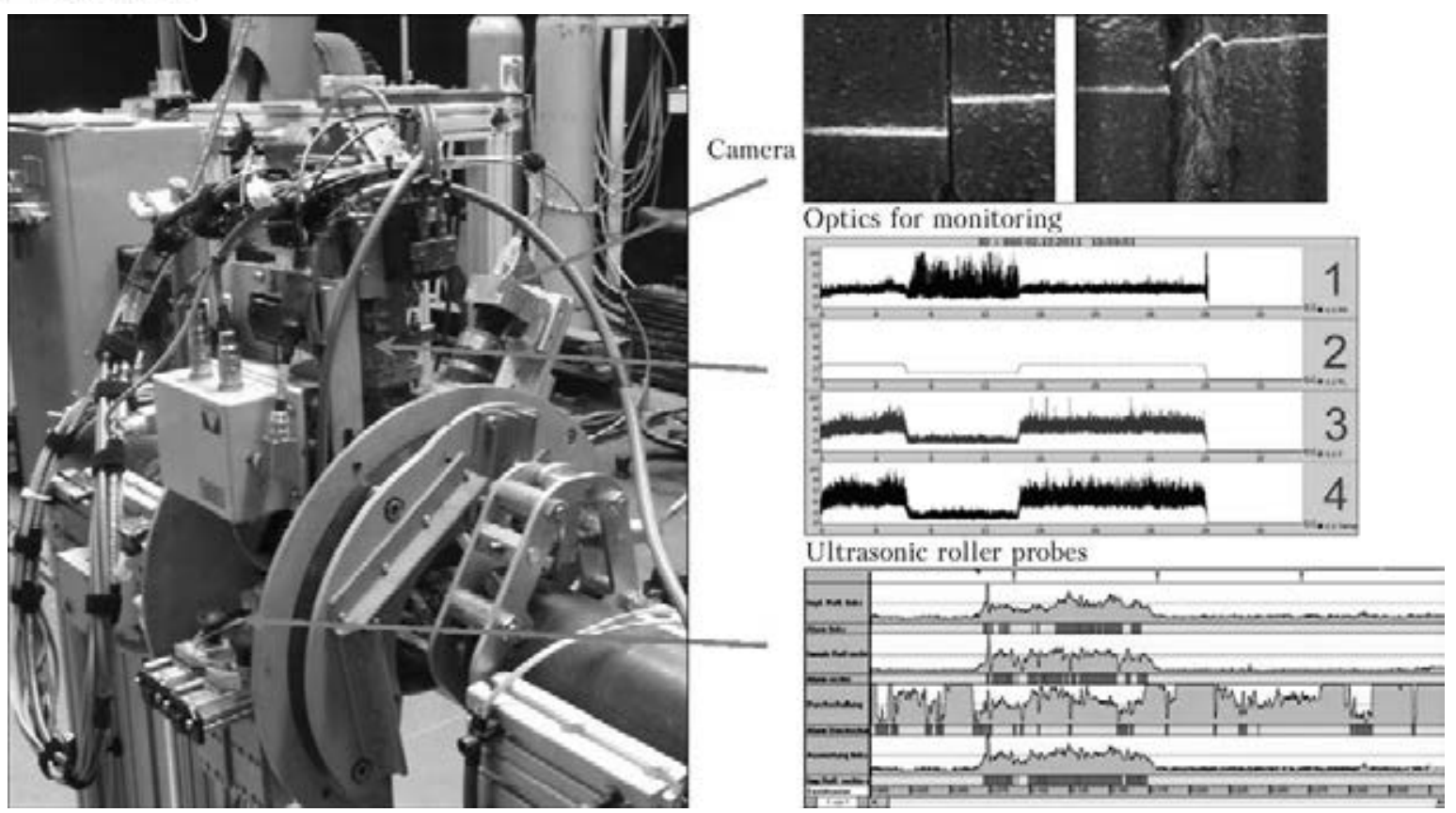

Figure 6. Specialized prototype equipment with camera, laser optics and ultrasonic test device

quality of the joint preparation with regard to geometry (presence of gap or poor edge alignment) and the standard of cleanliness.

As the first step, design and layout of the suitable construction was developed, for transforming the circumferential movement of the laser optics on pipe, including the clamping technique, required for joining and fixing the pipes of rated diameter from 80 to $150 \mathrm{~mm}$ with wall thicknesses of $2-5 \mathrm{~mm}$.

The construction consists of four ring-shaped plates, open downwards in order for joined pipes to be laid on them. Two outer plates are each

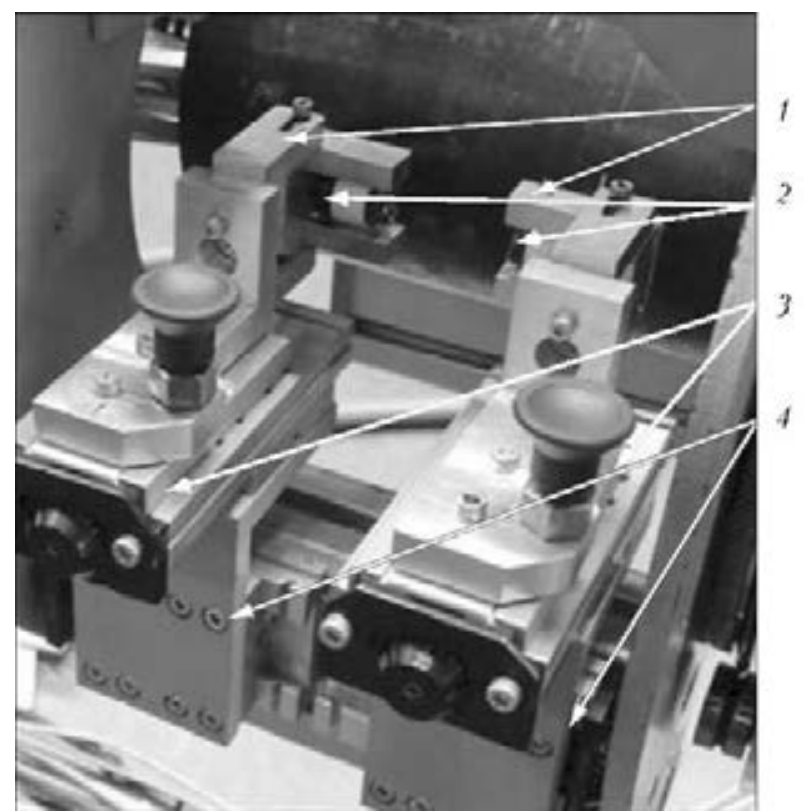

Figure 7. Ultrasonic test device: 1 - holding device for ultrasonic probes; 2 - ultrasonic roller probes; 3 - axes for coarse height adjustment; 4 - axes for adjusting distance to the welded joint connected to one of the pipes by means of clamping device. Two inner rings are guided along them, so that circular movement around the pipes can be carried out. Two inner rings are rigidly connected to one another. Arranged between these rings are all the components, which carry out the joining and testing procedures (Figure 6).

The core of experimental arrangement is the Precitec transmitting processing optical unit of YW30 type, from with sensor array, integrated coaxially to the path of beam, for photo-optical acquisition of relevant emissions from laser welding process. This processing optical array was adapted to the construction for the purpose of experiment.

For the assessment of weld, in particular with regard to edge alignment and gap, the bead, produced by line laser transverse to the joint, is recorded by camera. The camera and line laser are located close to the laser optic centrally between two inner plates of the carrier system, and are guided around the pipe with circumferential movement. Following the welding process, the same camera is used to record the topography of weld. In this situation, particular attention is paid to the gap and edge alignment at preparation for welding, geometrical seam irregularities and welding defects open to the outside.

The ultrasonic inspection equipment, used in investigations, is made up of actual ultrasonic testing instrument and roller angle beam probes. The testing instrument is a multi-channel ultrasonic system with five channels, separated from one another with the aid of a multiplexer. In 

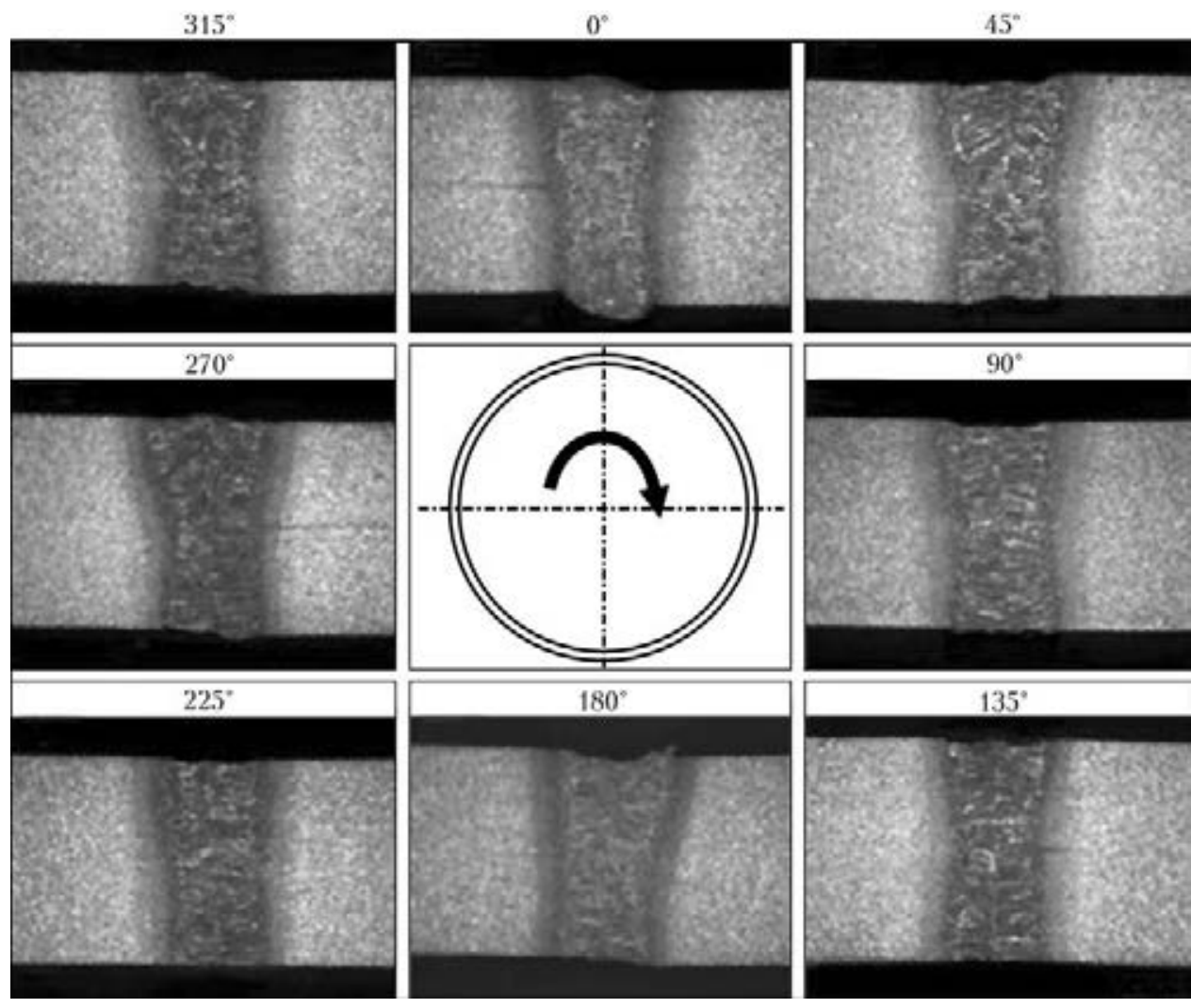

Figure 8. Macrosections of welded joint specimens with various pipe bend angle (3.5 times magnification)

addition, special roller angle beam probes are used for oblique application of ultrasonic with $55^{\circ}$ angle and $6 \mathrm{MHz}$ frequency. These probes are characterized in that the effective coupling is carried out not with the aid of couplants but by way of silicone tyre. The probe is moved on this tyre above the component, whereby only a movement parallel to the seam can be carried out.

In the final project phase, the individual systems, which had been developed consisting of welding optics, camera for recording the joint topography and process monitoring, as well as arrangement for the ultrasonic roller probes were all brought together to form a complete prototype solution.

For the direct evaluation of internal weld irregularities, two ultrasonic roller probes are guided around the pipe at defined interval from one another, left and right of the seam. Figure 7 shows the arrangement of ultrasonic test device.

Contact between the ultrasonic roller probes and the pipe is maintained by means of spring tension. Height adjustment is possible for different pipe diameters.

Results of material testing. In order to determine the mechanical-technological characteristic values of the laser-welded pipe joint, a series of experiments were carried out under ideal conditions for pipe edge preparation and without any provoked defect settings. After the produc-
Table 4. Mechanical properties of the L360NB steel welded joints

\begin{tabular}{|c|c|c|c|c|c|}
\hline \multirow{2}{*}{\multicolumn{2}{|c|}{$\begin{array}{l}\text { Specimen } \\
\text { location }\end{array}$}} & \multicolumn{2}{|c|}{ Dimensions, mm } & \multicolumn{2}{|c|}{$K C V, \mathrm{~J}$} \\
\hline & & Width & Height & Individual & Mean \\
\hline \multicolumn{6}{|c|}{ Charpy impact test at $T=0{ }^{\circ} \mathrm{C}$} \\
\hline \multirow{6}{*}{\multicolumn{2}{|c|}{ Weld }} & 3.4 & 8.0 & 59 & 62 \\
\hline & & 3.4 & 8.0 & 75 & \\
\hline & & 3.4 & 8.0 & 53 & \\
\hline & & 3.4 & 8.0 & 79 & 71 \\
\hline & & 3.4 & 8.0 & 66 & \\
\hline & & 3.4 & 8.0 & 68 & \\
\hline \multicolumn{6}{|c|}{$\mathrm{V}$-notched bar impact test at $T=0{ }^{\circ} \mathrm{C}$} \\
\hline \multirow[t]{6}{*}{ HAZ } & & 3.4 & 8.0 & 63 & \multirow[t]{3}{*}{55} \\
\hline & & 3.4 & 8.0 & 56 & \\
\hline & & 3.4 & 8.0 & 45 & \\
\hline & & 3.4 & 8.0 & 40 & \multirow[t]{3}{*}{41} \\
\hline & & 3.4 & 8.0 & 42 & \\
\hline & & 3.4 & 8.0 & 41 & \\
\hline \multicolumn{6}{|c|}{ Transverse tensile test } \\
\hline Specimen & $\sigma_{\mathrm{y}}, \mathrm{MPa}$ & $\sigma_{\mathrm{t}}, \mathrm{MPa}$ & $\delta, \%$ & $\psi, \%$ & $\begin{array}{c}\text { Fracture } \\
\text { site }\end{array}$ \\
\hline 1 & 448 & 487 & 20.1 & 70 & $\mathrm{BM}$ \\
\hline 2 & 418 & 467 & 24.5 & 70 & $\mathrm{BM}$ \\
\hline 3 & 416 & 466 & 21.6 & 67 & BM \\
\hline 4 & 413 & 463 & 25.8 & 62 & $\mathrm{BM}$ \\
\hline
\end{tabular}


tion of this reference sample, metallographic specimens were taken in increments of $45^{\circ}$, divided over the circumference. These are shown in Figure 8, related to the pipe angle in each case.

As can clearly be seen, for the parameters selected no influence derives from the orbital constantly changing welding position, which supports the constant signal level of the process monitoring system. This analysis relates both to the weld geometry in respect of its upper and lower side, as well as to the occurrence of internal weld irregularities. As a result it can be estimated that, under the conditions chosen, an evaluation group B according to DIN EN ISO 13919-1 is fulfilled.

The investigations for determining the static weld strength and toughness, making reference to the DVGW Worksheet GW 350, likewise did not reveal any anomalies. The values, determined accordingly in the tensile and $\mathrm{V}$-notched bar impact test (undersize samples) for L360NB steel $5 \mathrm{~mm}$ thick are given in Table 4 .

\section{Summary}

In order to increase efficiency in pipeline construction, examinations of new welding processes for joining of pipes are indispensable with the focus on increasing the welding speed at a reduced number of passes. Possible alternatives are the laser and hybrid laser-GMA welding processes since due to development of fiber laser, the beam source with new fields of application is available [2].

The objective of investigations presented was to prove the principal suitability of laser-based processes for pipeline construction, as well as the behaviour of those processes in out-of-position welding, which is required for its application.

The results distinctively show the potential of laser welding technology at high laser output and with brilliant beam qualities.
As an alternative of the existing approaches [3] there is the idea of using the hybrid process for production of high quality root pass at 12$15 \mathrm{~mm}$ root faces. This approach is the basis of examinations currently performed.

As a result of the work presented for the development of in-situ testing and monitoring strategy for laser-based pipe welding, the function and suitability have been proved at the laboratory level. In specific terms, this means that the ability to test laser-welded joints by means of ultrasonic technology can also be achieved in the $3-5 \mathrm{~mm}$ range of wall thicknesses for critical irregularities, such as lack of fusion, root defects (lack of penetration), and porosity. In the final arrangement of equipment, it was shown that the interaction of individual systems of the camera, photooptical process monitoring and ultrasonic testing is indeed achieved. This was proved in the error simulations. Further optimization of the assessable sizes of irregularities in the weld is foreseeable in the further course of the work.

Acknowledgements. The authors gratefully acknowledge funding of the German Federal Ministry of Economics and Technology.

1. Blackman, D., Dorling, V., Howard, R. (2002) High-speed tandem GMAW for pipeline welding. In: 4th Int. Pipeline Conf. Proc. (Calgary, Alberta, Canada), 517-523.

2. Keitel, S., Neubert, J., Stroefer, M. (2009) Laserbased girth welding technologies for pipelines GMAW gets support. In: Proc. of IIW Int. Conf. on Advances in Welding and Allied Technologies (Singapore), 289-294.

3. Gumenyuk, A., Gook, S., Lammers, M. et al. (2009) High power fibre laser welding for pipeline applications. In: Proc. of 5th Int. Congress on Laser Advanced Materials Processing. 